\title{
GESTÃO MUNICIPAL DA EDUCAÇÃO: LÓGICAS DE SOBREVIVÊNCIA E DE DESENVOLVIMENTO ESTRATÉGICO
}

\author{
Aleixo Augusto Figueiras Simões ${ }^{1}$ \\ Fernando Ilídio Ferreira ${ }^{2}$
}

\begin{abstract}
RESUMO: A relação entre Educação e Desenvolvimento constituiu a temática deste artigo, que, através da análise documental das Cartas Educativas dos nove concelhos da Beira Interior Norte NUT III, perscruta as representações, tendências e tensões patentes nas propostas apresentadas. Uma ideia sobressaiu: a premência dos problemas faz com que a ação municipal se situe entre o estabelecimento de patamares de sobrevivência e a implementação de estratégias com vista à garantia da estabilidade mínima para o futuro.
\end{abstract}

Enunciámos uma das principais tensões em duas palavras-chave do título: sobrevivência e estratégia. Estamos perante uma situação em que os problemas do território, em boa verdade, já não dependem da ação dos seus intervenientes diretos, limitando-se estes, frequentemente, a menorizar e a resolver pontualmente situações de pré rutura ou rutura, especialmente a variável demográfica. Consideramos, no entanto, que só através de políticas de âmbito mais global (políticas nacionais, locais e transnacionais, nomeadamente da União Europeia), que valorizem estes territórios do Interior, conjugando serviços públicos de apoio, valorizando as relações de proximidade e descriminando positivamente estes espaços, se conseguirá inverter estas tendências, resolvendo simultaneamente dois problemas: o do Interior com um 'repovoamento' e melhoria dos seus apports competitivos e o do Litoral que enferma de uma excessiva concentração populacional, ficando assim menos congestionado e de mais fácil gestão. É neste contexto que poderemos

\footnotetext{
${ }^{1}$ Mestre em Ciências da Educação, Especialização em Administração e Organização Escolar, Universidade Católica Portuguesa (Centro Regional das Beiras, Pólo de Viseu); dissertação concluída em 2010. E-mail: aleixosimoes@gmail.com

2 Professor Associado da Universidade do Minho, Instituto de Educação. E-mail: filidio@ie.uminho.pt
} 
encarar a atuação dos municípios na área educativa: por um lado, procuram garantir os níveis mínimos de sobrevivência dos serviços destinados aos seus munícipes, e, por outro, intentam arquitetar estratégias que permitam visualizar uma 'janela de esperança' para inverter o rumo dos acontecimentos.

Palavras-chave: Gestão Municipal, Desenvolvimento, Carta Educativa

\begin{abstract}
The connection between Development and Education is the thematic of this article which presents an analysis of the Educational Charters' of the nine municipalities from the North of Beira Interior - NUT III, aiming to investigate the representations, tensions and trends from the proposals presented in these documents. An idea stands out: the urgency of the problems makes the municipal action be located between the setting of survival and the implement of strategies ensuring the minimum stability for the future.

The main tensions were defined in two keywords which are part of the title: survival and strategy. We are facing a situation where land problems are indeed no longer dependent on its direct interveners who frequently only but lessen and solve pre-disruptive or disruptive situations, (especially the demographic ones). However, we consider that only through more global policies (local, national and foreign policies, namely from EU) that value these inland territories together with supportive public services, praising the close relationships and positively discriminating these areas, one will manage to reverse these trends and simultaneously, solve both problems: the Interior, by a 'repopulation' and improvement of its competitive apports and the Coastland that suffers from an excessive concentration of people, being therefore less crowded and more manageable. Within this context, we will consider the action of the municipalities in the educational field: on the one hand, they seek to guaranty the minimum surviving levels of their citizens' services, and on the other hand, to scheme strategies that let them envision a 'window of hope' to reverse the course of events.
\end{abstract}

Key words: Municipal Management, Development, Educational Charter

\title{
1. AS CARTAS EDUCATIVAS MUNICIPAIS COMO OBJETO DE ESTUDO
}

$\mathrm{Na}$ última década, fruto de alterações políticas e de uma visão mais aprofundada do que se entendia ser o papel das autarquias locais na área educativa, surge o Conselho Municipal de Educação, que alarga o âmbito do conceito educativo e obriga à formulação de um documento reflexivo/estratégico (Carta Educativa - CE) considerado uma pedra basilar do sistema educativo local. Como tal, as Cartas Educativas (CE) devem/deveriam incluir e rentabilizar os recursos, incentivando a 
participação dos diversos parceiros sociais, devendo as comunidades educativas ser analisadas e perspetivadas enquanto campo de cooperação entre o sistema educativo e o sistema económico e social.

"A CE é, a nível municipal, o instrumento de planeamento e ordenamento prospetivo de edifícios e equipamentos escolares a localizar no concelho, de acordo com as ofertas de educação e formação que seja necessário satisfazer, tendo em vista a melhor utilização dos recursos educativos, no quadro do desenvolvimento demográfico e sócio económico de cada município" (art. 10 do Decreto-Lei n. ${ }^{\circ}$ 7/2003 de 15 de Janeiro). O artigo $11 .^{\circ}$ deste mesmo diploma estabelece para a CE os seguintes objetivos:

(1) Visa assegurar a adequação da rede de estabelecimentos de educação pré-escolar e de ensino básico e secundário a nível municipal;

(2) É o reflexo, a nível municipal, do processo de ordenamento a nível nacional da rede de ofertas de educação e formação, num contexto de descentralização administrativa, de reforço dos modelos de gestão dos estabelecimentos de educação e de ensino públicos e respetivos agrupamentos e de valorização do papel das comunidades educativas e dos projetos educativos das escolas;

(3) Deve promover o desenvolvimento do processo de agrupamento de escolas, com vista à criação, nestas, das condições mais favoráveis ao desenvolvimento de centros de excelência e de competências educativas, bem como as condições para a gestão eficiente e eficaz dos recursos educativos disponíveis;

(4) Deve incluir uma análise prospetiva, fixando objetivos de ordenamento progressivo, a médio e longo prazo;

(5) Deve garantir a coerência da rede educativa com a política urbana do município.

A ideia da CE, cuja origem está associada ao referido normativo de 2003 e à formação dos Conselhos Municipais de Educação, surge para dar corpo a uma política de valorização do 'local', subjacente a uma ideia de democracia participativa, que favoreça um maior envolvimento das pessoas e das comunidades, num esforço comum, com vista ao desenvolvimento integrado e sustentável dos territórios; uma aspiração de construção de um espaço próprio de afirmação dos contextos da ação concreta, numa perspetiva de autonomia em relação a um Estado tradicionalmente centralista e burocrático. Nesta ótica, a CE afirma-se (ou visava afirmar-se) como um instrumento de reflexão e assunção de causas locais, numa linha de 'afirmação do local', que tem como fim último o desenvolvimento local/regional e a criação de estruturas que permitam 
uma melhor qualidade de vida aos seus habitantes, ambicionando a meta dos designados "meios inovadores", com a valorização das potencialidades de um território (exploração de certas vantagens ou criação de novas oportunidades). Diga-se, no entanto, que a problemática em estudo se situa num quadro de valorização do local, mas sem ignorar o contexto mais amplo do Estado e dos fenómenos da globalização.

As CE refletem (ou poderiam/deveriam refletir) uma estratégia de atuação na qual estão contempladas as grandes linhas orientadoras do seu desenvolvimento educativo, em consonância com um desenvolvimento global, definindo os seus objetivos, de acordo com as características e as potencialidades do espaço abrangido. A noção de planeamento estratégico é, pois, inerente à construção de uma CE. Esta deve/deveria conter mecanismos de estimulação das potencialidades do território, de atração de novos recursos, de valorização das suas capacidades endógenas (humanas, de capitais e de informação), num contexto assumido em que existe uma 'competição' territorial com espaços circundantes, instituindose como reguladoras de dinâmicas de evolução territorial, preferencialmente diferenciadas e singulares.

Não apenas ao nível dos princípios, mas sobretudo no plano da ação concreta, as CE poderiam/deveriam refletir uma estratégia concertada e integrada de desenvolvimento regional e local. Por exemplo, no que concerne ao reordenamento da rede escolar, vivemos tempos em que, por motivos de racionalização do sistema educativo em geral, e da rede escolar em particular, o Interior (especialmente) vê encerrar muitas das suas escolas do $1^{\circ}$ ciclo do ensino básico, muitas vezes à revelia das vontades locais, fazendo tábua rasa do que está determinado nas respetivas $\mathrm{CE}$, impondo uma reflexão sobre as urgências do momento que parecem sobrepor-se à visão atempada e do planeamento prospetivo que aqueles documentos pressupunham aquando da sua elaboração localmente participada. Neste sentido, compreender os mecanismos que presidiram à elaboração do documento anunciador da identidade educativa do lugar - a Carta Educativa - perspetivando-o numa lógica global de Desenvolvimento Local, afigura-se-nos de extrema importância. Centrando o nosso interesse na importância do 'local' e da respetiva sociedade civil, e olhando para a proposta das $\mathrm{CE}$, consideramos que existe um 'novo' papel dos municípios na construção de uma política educativa local que, aliás, está consagrada na Constituição da República

\footnotetext{
${ }^{3} \mathrm{O}$ conceito de "meio inovador" refere-se a um fenómeno espacial resultante de novos processos e sinergias que ocorrem em territórios delimitados. Define-se por um conjunto de relações que ligam o sistema produtivo local, o conjunto de atores e representantes e a estrutura industrial. Unidos, estes fatores, geram uma dinâmica de desenvolvimento local e de aprendizagem coletiva (Camagni, 1999).
} 
Portuguesa, que define as suas competências e atribuições. É neste contexto de construção de uma "identidade" e "individualidade" de um território específico (NUT III - Beira Interior Norte-BIN) que pretendemos analisar as $\mathrm{CE}$ tendo como preocupação primordial a leitura crítica do que cada território faz da sua vertente educativa/formadora enquanto dispositivo de Desenvolvimento Local. Para nortear esta pesquisa, formula-se a seguinte questão/problema de investigação: Estará contemplada na Carta Educativa uma visão estratégica de desenvolvimento do sistema educativo local, integrando-a numa perspetiva mais vasta de desenvolvimento municipal?

\section{O CONTEXTO E A METODOLOGIA DO ESTUDO}

\subsection{O Contexto}

Não é nossa intenção fazer aqui uma descrição pormenorizada das características do contexto observado, pois ele apresenta-se em grande medida com homogeneidade física, económica, cultural e social. Opta-se por isso por uma análise SWOT (Strengths, Weaknesses, Opportunities, Threats / Forças, Fraquezas, Oportunidades, Ameaças), onde se relevam as nuances mais limitadoras/ ameaçadoras, ou as potencialidades/ oportunidades existentes.

Pese embora esta opção de princípio, existem alguns aspetos que, pela sua 'força condicionadora' das decisões, merecem ser aqui realçados, podendo o "espaço" em análise ser caraterizado em seis elementos básicos:

(1) Um espaço de periferia, com níveis de desenvolvimento assimétrico em relação ao país;

(2) Um espaço em baixa densidade (região pobre no contexto nacional - nas variáveis do PIB/per capita e do poder de compra; desertificação e envelhecimento populacional; variação negativa da população residente; deficit de desenvolvimento e iniciativa empresarial; deficit de capital humano qualificado);

(3) Um espaço de base económica agrícola, com alguns serviços de suporte à população, e em que a atividade industrial é exígua, e baseado em recursos endógenos tradicionais;

(4) Um espaço de fronteira ('border space') que, embora seja potencialmente vantajoso, sofre de um afastamento relativamente aos eixos centrais de desenvolvimento; 


\section{Quadro 1}

Matriz SWOT - Território e Recursos Endógenos

\begin{tabular}{|c|c|}
\hline $\begin{array}{l}\text { FORCAS } \\
\text { - Posicionamento } \\
\text { geoestratégico favorável para } \\
\text { a localização de } \\
\text { investimentos e projectos } \\
\text { estruturantes de alcance } \\
\text { regional e nacional; } \\
\text { - Bom nível de acessibilidade } \\
\text { inter-regional e nacional por } \\
\text { via rodoviária; } \\
\text { - Boa conectividade viária } \\
\text { inter-concelhia; } \\
\text { - Posicionamento de charneira } \\
\text { entre a Serra da Estrela e o } \\
\text { Douro; } \\
\text { - A existência de um } \\
\text { património histórico milenar } \\
\text { - riqueza e diversidade } \\
\text { paisagística; à principal } \\
\text { - Proximidade à } \\
\text { fronteira com Espanha; } \\
\text { - Condições naturais para } \\
\text { instalação de parques de } \\
\text { energia eólica. }\end{array}$ & $\begin{array}{l}\text { OPORTUNIDADES } \\
\text { - Relações de complementaridade estratégica } \\
\text { mais eficazes entre a Serra da Estrela e o } \\
\text { Douro, designadamente em matéria de } \\
\text { desenvolvimento turístico; } \\
\text { - Consolidação da influência da Guarda } \\
\text { (enquanto pólo central) no relacionamento } \\
\text { direto com as instituições e o mercado } \\
\text { espanhol; } \\
\text { - Reforço do potencial geoestratégico; } \\
\text { - Construção de novas vias rodoviárias } \\
\text { estruturante, a norte do distrito, } \\
\text { potenciando novas conectividades com o } \\
\text { norte do país; R Reforço da atratividade da região; } \\
\text { - Maior diálogo político e o reforço da } \\
\text { cooperação estratégica. }\end{array}$ \\
\hline 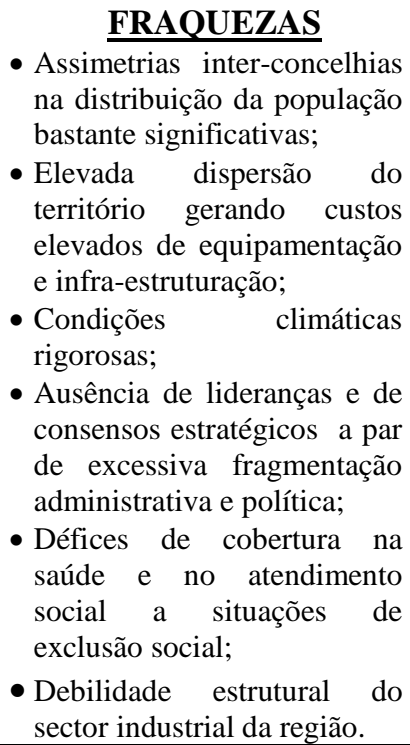 & $\begin{array}{l}\text { AMEAÇAS } \\
\text { - Agravamento dos movimentos de } \\
\text { concentração populacional nos núcleos } \\
\text { urbanos e abandono das zonas rurais; } \\
\text { - Endividamento e falta de capacidade } \\
\text { financeira das autarquias para aproveitar as } \\
\text { oportunidades ainda existentes no QREN; } \\
\text { - Reforço do centralismo político; } \\
\text { - Aumento da desertificação e consequente } \\
\text { empobrecimento das áreas rurais do } \\
\text { distrito, bem como o enfraquecimento da } \\
\text { posição relativa de várias autarquias. }\end{array}$ \\
\hline
\end{tabular}


(5) Um espaço de ausência estratégica global devido à inexistência de consensos políticos, com fracos índices de cooperação intermunicipal;

(6) Um espaço de poucas oportunidades de investimento e de emprego.

A génese destes problemas típicos do Interior nacional, segundo Ferrão (1997), centram-se fundamentalmente nos seguintes níveis: população envelhecida e globalmente pouco qualificada; tecido empresarial fragmentado e atomizado; um aparelho administrativo público constituído por entidades demasiado autocentradas e sem poder real de decisão; um movimento associativo incipiente, tanto do ponto de vista das empresas como dos cidadãos.

\section{Quadro 2}

Matriz SWOT - Competitividade e Emprego

\begin{tabular}{|c|c|}
\hline FORCAS & OPORTUNIDADES \\
\hline $\begin{array}{l}\text { - Aumento do nível médio de } \\
\text { qualificação da população ativa; } \\
\text { - Existência de vias estruturantes na } \\
\text { região, que reforçam as } \\
\text { conectividades a nível regional e } \\
\text { nacional; } \\
\text { - Valorização das produções } \\
\text { agroalimentares com certificação de } \\
\text { qualidade e origem; } \\
\text { - Existência de empresas, no território, } \\
\text { com projeção regional e nacional; } \\
\text { - Aumento da rede de serviços e do } \\
\text { emprego neste sector; } \\
\text { - Diversidade do valor dos recursos } \\
\text { patrimoniais e turísticos da região; } \\
\text { - Aumento do peso da oferta turística } \\
\text { no emprego e no tecido empresarial; } \\
\text { - Proximidade aos pólos de } \\
\text { desenvolvimento da Serra da Estrela } \\
\text { e do Douro Património Mundial; } \\
\text { - Potencialidades naturais } \\
\text { ambientais; e } \\
\text { - Proximidade à fronteira e ao mercado } \\
\text { espanhol. }\end{array}$ & $\begin{array}{l}\text { - Criação de medidas de } \\
\text { descriminação positiva, no } \\
\text { interior, destinada a favorecer a } \\
\text { localização empresarial, } \\
\text { designadamente de base fiscal; } \\
\text { - Crescimento dos fluxos turísticos } \\
\text { de forma consistente na Serra da } \\
\text { Estrela e no Douro, com novos } \\
\text { investimentos qualificados; } \\
\text { - Aumento da capacidade de } \\
\text { receção de novos investimentos } \\
\text { eólicos; enaior } \\
\text { - Consolidação } \\
\text { qualificação da oferta } \\
\text { museológica no território; } \\
\text { - Aproveitamento dos instrumentos } \\
\text { financeiros do QREN centrados } \\
\text { na valorização dos recursos } \\
\text { endógenos; } \\
\text { - Melhoria da articulação política } \\
\text { entre os diversos atores do } \\
\text { território; } \\
\text { - Reforço da cooperação } \\
\text { institucional com Espanha e } \\
\text { favorecimento das trocas } \\
\text { comerciais e turísticas com o } \\
\text { mercado do país vizinho; } \\
\text { - Qualificação da oferta comercial } \\
\text { e de serviços. }\end{array}$ \\
\hline
\end{tabular}




\begin{tabular}{|c|c|}
\hline $\begin{array}{l}\text { FRAQUEZAS } \\
\text { - Nível médio das habilitações } \\
\text { académicas relativamente baixo; } \\
\text { - Predomínio das microempresas de } \\
\text { natureza familiar; } \\
\text { - Distância em relação aos mercados } \\
\text { de consumo e escassez de logística; } \\
\text { - Superfície agrícola útil } \\
\text { desaproveitada; } \\
\text { - Declínio das atividades agropecuárias } \\
\text { e predomínio da agricultura de } \\
\text { subsistência; } \\
\text { - Estrutura comercial envelhecida e na } \\
\text { generalidade obsoleta; } \\
\text { - Insuficiência de espaços comerciais } \\
\text { com alguma dimensão orientados } \\
\text { para consumos urbanos; } \\
\text { - Subsector da construção civil cada } \\
\text { vez mais dependente das obras } \\
\text { públicas; } \\
\text { - Perda de importância da indústria } \\
\text { têxtil em termos de emprego e } \\
\text { estabelecimentos; } \\
\text { - Ausência de políticas públicas de } \\
\text { incentivo a investimento } \\
\text { empresarial. ao in a }\end{array}$ & $\begin{array}{l}\text { AMEACAS } \\
\text { - Dificuldade de atração e fixação } \\
\text { de unidades industriais e } \\
\text { empresariais, no quadro das } \\
\text { debilidades estruturais existentes; } \\
\text { - Incapacidade de adaptação às } \\
\text { condições de mercado dos } \\
\text { produtores agrícolas e da } \\
\text { indústria agroalimentar, bem } \\
\text { como, às exigências da } \\
\text { regulamentação; } \\
\text { - Inexistência de políticas de } \\
\text { descriminação positiva; } \\
\text { - A imposição de portagens na A23 } \\
\text { e na A25; } \\
\text { - Perca de } \\
\text { geoestratégica; } \\
\text { - Falta de procura dos parques e } \\
\text { zonas industriais existentes; } \\
\text { - Continuação da política de rutura } \\
\text { e de diálogo surdo entre os atores } \\
\text { políticos no distrito; } \\
\text { - Ameaça de crescimento do } \\
\text { desemprego estrutural. }\end{array}$ \\
\hline
\end{tabular}

\subsection{A Metodologia}

A pesquisa aqui desenvolvida inscreve-se num paradigma centrado na análise e compreensão dos fenómenos sociais, ao mesmo tempo que privilegia uma abordagem dinâmica do desenvolvimento local, desenrolando-se em torno do discurso formal dos protagonistas (os atores locais), num contexto definido a partir de matrizes territoriais, políticas e socioeconómicas. Estamos perante um 'Estudo de Caso' (Yin, 2005), baseado numa realidade territorial regional/local, embora consubstanciando-se num fenómeno nacional. Sabendo que um estudo de caso pode não ser representativo de uma população determinada, o seu interesse não é o da generalização mas o da investigação sistemática de uma situação específica. Preferimos, assim, apostar na especificidade local, sem tentações de abrangência da realidade nacional; no entanto, e dado que esta matriz de situações é mais generalizada e abrangente do que a circunscrição à área em estudo, talvez se possam extrair daqui elementos de referência para o todo nacional. 
Optar pela escolha de um determinado foco "é sempre um ato artificial, uma vez que implica a fragmentação do todo onde ele está integrado" (Bogdan \& Biklen, 1994, p. 91). Efetivamente, "na procura de um contexto ou tema para um estudo de caso, sente-se frequentemente um dilema quanto ao local onde encontrar a chamada situação 'típica', ou a situação "atípica"” (p. 94). No caso concreto deste trabalho, em que se estudam várias unidades de análise (concelhos), estamos perante um "estudo de caso múltiplo", que permite alguma comparação, baseando-se na amplitude e na presença ou ausência de algumas características particulares ou gerais.

À luz da questão/problema atrás enunciado e dos objetivos do estudo, definimos as seguintes hipóteses de investigação (Quadro 3).

\section{Quadro 3}

Objetivos e hipóteses de estudo

\begin{tabular}{|c|c|}
\hline Objetivos gerais & Objetivos específicos \\
\hline $\begin{array}{l}\text { Enumerar os } \\
\text { 'problemas' } \\
\text { educativos. }\end{array}$ & $\begin{array}{l}1.1 \text { - Identificar as áreas consideradas como problemáticas } \\
\text { para a ação dos municípios na área educativa; }\end{array}$ \\
\hline $\begin{array}{l}\text { Reconhecer a } \\
\text { noção de } \\
\text { 'Educação'. }\end{array}$ & $\begin{array}{l}2.1 \text { - Identificar a conceção municipal de 'Educação'; } \\
2.2 \text { - Descrever a relação existente entre o município e as } \\
\text { estruturas educativas concelhias; }\end{array}$ \\
\hline $\begin{array}{l}\text { Conhecer as } \\
\quad \text { ações } \\
\text { desenvolvidas } \\
\text { pelos municípios. }\end{array}$ & $\begin{array}{l}3.1 \text { - Identificar os recursos educativos existentes; } \\
3.2 \text { - Tipificar as linhas de atuação do município; } \\
\text { 3.3 - Caracterizar a articulaça entre o sistema educativo local } \\
\text { e outras políticas sociais (saúde, ação social, formação e } \\
\text { emprego); } \\
\text { 3.4 - Enunciar os constrangimentos ao desenvolvimento local } \\
\text { em geral e educativo em particular; }\end{array}$ \\
\hline $\begin{array}{c}\text { Identificar } \\
\text { estratégias } \\
\text { implementadas/a } \\
\text { implementar na } \\
\text { área educativa. }\end{array}$ & $\begin{array}{l}4.1 \text { - Averiguar da existência de propostas de colaboração inter- } \\
\text { concelhias; } \\
4.2 \text { - Identificar as opções de desenvolvimento futuro para o } \\
\text { municipio e a sua articulação com outros setores de } \\
\text { atividade; } \\
\text { 4.3 - Averiguar da sensibilidade para novas oportunidades de } \\
\text { 'desenvolvimento induzido'. }\end{array}$ \\
\hline
\end{tabular}

Definidos os objetivos do estudo, os métodos e técnicas de investigação deverão adequar-se aos mesmos. De acordo com a perspetiva de Almeida (1995) as técnicas de observação constituem-se como conjuntos de procedimentos bem definidos e transmissíveis, tendo por fim a obtenção de certos resultados derivados da atividade de pesquisa. $\mathrm{O}$ procedimento adotado para a realização deste estudo foi a análise documental. Segundo Bardin (1977), a análise documental é "um conjunto de operações visando representar o conteúdo de um documento 
sob a forma diferente do original, a fim de facilitar num estudo ulterior, a sua consulta e referenciação" (1977, p. 45). No entanto, um documento pode ser algo mais do que um pergaminho poeirento, ou seja, este termo designa todas as fontes de informações já existentes (Laville \& Dionne, 1999). De salientar a existência de um aspeto importante na análise documental: todos os documentos proporcionam o surgimento da informação não inteligente, cabendo ao investigador tentar avaliar o seu significado preciso (Duffy, 1997).

A análise documental caracterizou-se pela análise exclusiva das CE dos concelhos inseridos no estudo (nove). O nosso principal interesse foi o de compreender o modo como os municípios estão a exercer as suas competências em matéria de educação, assim como se projetam temporal e estrategicamente no futuro, na área educativa, em articulação com o desenvolvimento local. Também de assinalar que esta análise somente tem em linha de conta o 'produto final' (CE), não se atendendo a todo o processo negocial (necessariamente de compromisso), que poderia conter elementos relevantes para a compreensão do fenómeno. Por último, e atendendo à data de execução e aprovação das CE (algumas com cerca de cinco anos de existência) e dadas as transformações socioeconómicas entretanto surgidas, é de admitir a sua inexequibilidade nas atuais condições (quer em termos do sistema educativo, quer político).

Para a seleção da unidade de análise, contribuiu o conhecimento pessoal da realidade regional e local, não só por ser área de trabalho/residência, mas também porque outros trabalhos de investigação entretanto desenvolvidos permitiram considerá-la como um 'território' polarizado num município central e onde as várias unidades de estudo enfrentam um conjunto de obstáculos ao desenvolvimento em muito semelhantes. A área escolhida circunscreve-se, como já dissemos, à NUT III - Beira Interior Norte - composta pelos concelhos de Almeida, Celorico da Beira, Figueira de Castelo Rodrigo, Guarda, Manteigas, Mêda, Pinhel, Trancoso e Sabugal, todos eles integrados na NUT II Região Centro - e no distrito da Guarda.

O tratamento dos dados foi feito de acordo com os objetivos definidos e implicou o desenvolvimento de um sistema de codificação, na procura de regularidades e padrões, assim como de tópicos presentes nos dados, no que resultou a elaboração de 'categorias de codificação' (Bogdan \& Biklen, 1994, p. 221). Neste sentido foram utilizados 5 categorias:

(1) 'de Contexto' (categoria segundo a qual a maior parte da informação sobre o contexto, a situação, o 'tópico ou o tema podem ser classificados - ex. a descrição dos equipamentos existentes);

(2) 'de Definição de Situação' (conjuntos de dados que descrevem a forma como os sujeitos - municípios - definem a situação existente, na 
visão que estes têm do mundo e na forma como se veem a si próprios em relação à situação. Ex. objetivos a atingir?; Como se autodefinem?; O que é importante? Convicções sobre a sua atividade?);

(3) 'de Processo' (palavras e frases que facilitam a categorização das sequências de acontecimentos, mudanças ao longo do tempo ou passagens de um tipo ou género de estatuto para outro, apontando períodos de tempo, estádios, fases, passagens, passos, cronologias, de alguma maneira perspetivando mudanças na organização);

(4) 'de Atividade' (comportamentos que ocorrem regularmente e que são uma parte formal do meio);

(5) 'de Estratégia' (referem-se a táticas, métodos, caminhos, técnicas, manobras, tramas e outras formas conscientes de as pessoas realizarem várias coisas).

Consequentemente, foram elaborados quadros resumo que possibilitaram a análise e interpretação dos dados, bem como a elaboração das conclusões relativamente aos objetivos e hipóteses definidos.

\section{APRESENTAÇÃO E DISCUSSÃO DOS RESULTADOS}

A análise documental das nove CE que serviram de base à elaboração deste estudo empírico foi orientada no sentido de responder a três objetivos gerais: 1) Reconhecer noções de 'Educação' expressas nas CE; 2) Enumerar os problemas educativos valorizados pelos municípios; 3) Conhecer as ações desenvolvidas pelos municípios; 4) Identificar estratégias implementadas/a implementar pelos municípios na área educativa.

\subsection{Reconhecer as noções de 'Educação' expressas nas CE}

$\mathrm{Na}$ organização e denominação das diferentes noções de Educação foram consideradas as informações explícitas ou implícitas que pudessem ser enquadradas em cada uma das designações que a seguir se seguem no início de cada conceito. As referidas noções foram definidas segundo os 'códigos de codificação' (contexto, definição de situação, processo, atividade e estratégia).

a) Ligada ao conceito de Democracia - Segundo os princípios que emanam da própria Filosofia da Educação Moderna: igualdade de oportunidades, fraternidade, solidariedade e justiça social com o objetivo de "aprofundamento da democracia participativa"; 
b) Como factor de desenvolvimento - $\mathrm{Na}$ base de muitas $\mathrm{CE}$, quer para aquelas que a "consideram como prioridade política (...), reconhecendo a sua dimensão social porque transmite valores como a solidariedade, a igualdade de oportunidades, a participação social, além de contribuir para a democratização e a qualidade de vida", quer para os que consideram que a CE funcionará como um "instrumento de planeamento e ordenamento prospetivo no quadro de um desenvolvimento socioeconómico do Município";

c) Como localista / comunitária / cooperativista - "A escola, espaço privilegiado da ação educativa, necessita cada vez mais da conjugação de esforços entre os atores envolvidos no processo educativo e das autarquias", “... aponta no sentido de um envolvimento gradual, mas alargado, da comunidade local e de uma multiplicidade de agentes sociais locais", "por forma a potenciar os recursos locais, mas também promovendo formas integradas de intervenção social e sócioeducativa";

d) Como performativa / gestionária - Intimamente associada à visão de 'escola certificadora' que pretende 'medir', 'valorar', integrar institucionalmente o aluno, num sistema produtivo e avaliativo;

e) Como experimentalista / vanguardista - A procura de novos desafios ajustados à evolução dos tempos e "à promoção da qualidade e adequação do sistema educativo local aos desafios colocados por uma sociedade cada vez mais exigente com as competências dos seus cidadãos".

\subsection{Enumerar os 'problemas educativos' valorizados pelos Municípios}

a) A População Residente - o decréscimo da natalidade e o envelhecimento, o baixo nível de habilitações literárias, etc., constituem o 'problema' mais vezes enunciado nas $\mathrm{CE}$, sendo assumido como causa e consequência de toda a situação atual;

b) A Sustentabilidade Económica - está presente em todas as CE, atendendo a que existe uma grande debilidade do tecido empresarial, com fraca capacidade concorrencial, baseado numa mão-de-obra pouco qualificada e em que o setor primário tem vindo a ser continuamente desvalorizado na área do emprego;

c) O Território - Num território considerado difícil, em alguns casos mesmo propiciadores ao isolamento, as acessibilidades intra e interconcelhias adquirem uma importância estratégica, pois condicionam, em grande medida, as opções de concentração/desconcentração dos estabelecimentos de ensino; 
d) A Rede Escolar - É no conjunto daquilo que se pode considerar como estritamente ligado à gestão da rede escolar que os municípios manifestam uma maior incidência nas suas considerações, em áreas que vão desde a estruturação do número de estabelecimentos, à contabilização das 'performances' educativas, à construção e manutenção dos equipamentos constantes do parque escolar e às infraestruturas externas aos equipamentos escolares que poderão servir de apoio à ação educativa.

\subsection{Conhecer as ações desenvolvidas pelos Municípios}

$\mathrm{Na}$ organização e denominação dos diferentes tipos de atividade foram consideradas as principais notações em cada uma das $\mathrm{CE}$ segundo o critério de similitude em termos de objetivo a atingir. Esta análise incide nas vertentes da ação social, gestão do parque escolar e apoio a atividades/parcerias.

a) Ação Social - O Município "enquanto elemento de igualização das oportunidades entre os indivíduos enquadrados no âmbito do sistema educativo... reduzindo a vulnerabilidade em que se encontram estes territórios concelhios e, nessa medida, as populações neles residentes";

b) Gestão do parque escolar - Na gestão do parque escolar concelhio (construção, manutenção), os municípios consignam a esta atividade recursos muito significativos;

c) Apoio a atividades / parcerias - $\mathrm{O}$ apoio a atividades letivas/não letivas tem sido progressivamente incrementado $\mathrm{e}$ constitui-se como uma área de grande potencial de crescimento num futuro próximo.

\subsection{Identificar estratégias implementadas / a implementar na área educativa}

Dos elementos recolhidos nas CE, e numa dimensão prospetiva, é possível enquadrar as ações propostas em dois domínios distintos, embora concomitantes no tempo e no espaço:

(1) O curto/médio-prazo, com os imperativos de um melhor ajustamento das variáveis que estão de momento sob a sua jurisdição e interferência direta (parque escolar; rede escolar; oferta formativa e estabelecimento de redes de colaboração com os atores já implantados no terreno educativo);

(2) O médio/longo-prazo, com a criação de mecanismos mais abrangentes de desenvolvimento do território, onde as variáveis 
externas mais fazem sentir os seus efeitos e para as quais é necessário não só um período mais dilatado de tempo, como a necessidade de fatores exógenos propiciadores de um desenvolvimento local, em si mesmo indutores do desenvolvimento educativo concelhio.

Neste contexto, optámos por considerar as primeiras em termos de perspetivas de sobrevivência, porque implicam adaptações imediatas, e as segundas como perspetivas estratégicas, pois implicam um maior empenhamento e envolvimento de uma diversidade de atores (fundamentalmente externos) para a prossecução de objetivos mais ambiciosos e que garantam uma maior sustentabilidade no futuro.

Quanto às visões de sobrevivência, o conjunto de fatores, enquadrados num contexto de razoabilidade face aos contornos da situação existente, funda-se numa convicção de que existe uma estreita margem de manobra naquilo que é possível fazer, impulsionando os municípios para ações sobre 'o que existe' pretendendo retirar daí o máximo de rendibilidade face às projeções que são efetuadas para o curto/médio-prazo, das quais se destacam: a) Gestão / Manutenção de equipamentos escolares integrados na rede educativa concelhia; b) Colaboração com entidades concelhias na área educativa; c) Colaboração com entidades extraconcelhias na área educativa.

Relativamente às visões estratégicas (Quadro 4), para além das emergências do curto-prazo, que implicam uma racionalização e rentabilização dos meios ao seu dispor, os municípios apresentam um conjunto de propostas de âmbito mais vasto e mobilizador de entidades externas, que, com a efetivação de opções de ordem política, possibilitem desenhar cenários mais risonhos do que os existentes na situação atual, naquilo que poderemos considerar como uma visão estratégica de futuro sustentado. 


\section{Quadro 4}

Visões estratégicas

\begin{tabular}{|c|c|c|c|c|c|c|c|c|c|}
\hline \multirow{2}{*}{$\underline{\text { Itens }}$} & \multicolumn{9}{|c|}{ Concelhos } \\
\hline & C.1 & C. 2 & C. 3 & C. 4 & $\underline{\text { C. }}$. & C. 6 & C.7 & C. 8 & C. 9 \\
\hline $\begin{array}{l}\text { Acesso a todos à } \\
\text { educação e formação }\end{array}$ & & & & $\mathrm{X}$ & & & & $\mathrm{X}$ & \\
\hline $\begin{array}{l}\text { Aumentar } \\
\text { capacidade de atração }\end{array}$ & & & & $X$ & & & $\mathrm{X}$ & & \\
\hline $\begin{array}{l}\text { Qualificação do } \\
\text { território }\end{array}$ & $X$ & & & $\mathrm{X}$ & & & & & \\
\hline $\begin{array}{ll}\begin{array}{l}\text { Otimização } \\
\text { recursos }\end{array} & \text { dos } \\
\end{array}$ & $\mathrm{X}$ & & & $\mathrm{X}$ & & & & & \\
\hline $\begin{array}{l}\text { Repensar estratégias } \\
\text { de desenvolvimento }\end{array}$ & & & & & & & & $\mathrm{X}$ & \\
\hline $\begin{array}{lr}\text { Repensar } & \text { estratégias } \\
\text { de fixação da } & \text { da } \\
\text { população } & \\
\end{array}$ & & & & & & & & $\mathrm{X}$ & \\
\hline $\begin{array}{ll}\text { Requalificação } & \text { do } \\
\text { tecido económico }\end{array}$ & & & & $\mathrm{X}$ & & & & & $\mathrm{X}$ \\
\hline Diminuir o isolamento & & & & & & $\mathrm{X}$ & & & \\
\hline $\begin{array}{l}\text { Dinamismo } \\
\text { económico (problema) }\end{array}$ & & & & $\mathrm{X}$ & & $\mathrm{X}$ & & & \\
\hline $\begin{array}{lc}\text { Dispersão } & \text { do } \\
\text { povoamento } & - \\
\text { condicionante } & \\
\end{array}$ & & & & $X$ & & & & $X$ & \\
\hline $\begin{array}{lr}\text { Melhorar } & \text { fatores } \\
\text { competitivos } & \text { do } \\
\text { concelho } & \end{array}$ & & & $\mathrm{X}$ & $X$ & & & & & \\
\hline $\begin{array}{ll}\text { Enquadramento } & \text { no } \\
\text { PDM } & \end{array}$ & $\mathrm{X}$ & & & $\mathrm{X}$ & & & & & \\
\hline $\begin{array}{ll}\text { Promoção } & \text { de } \\
\text { processos } & \text { de } \\
\text { desenvolvimento } & \\
\text { integrado e sustentado }\end{array}$ & & & & $\mathrm{X}$ & & & $\mathrm{X}$ & & \\
\hline $\begin{array}{lr}\begin{array}{l}\text { Rentabilizar } \\
\text { (inter e }\end{array} & \text { recursos } \\
\text { concelhios) } & \\
\end{array}$ & & & & $\mathrm{X}$ & & $\mathrm{X}$ & & & \\
\hline $\begin{array}{lr}\text { Equipamento } & \text { - apoio } \\
\text { externo } & - \\
\text { investimentos } & \\
\end{array}$ & & & & & $\mathrm{X}$ & & & & \\
\hline $\begin{array}{l}\text { Redimensinamento } \\
\text { dos recursos }\end{array}$ & & $\mathrm{X}$ & & $\mathrm{X}$ & & & & & \\
\hline $\begin{array}{l}\text { Investimentos } \\
\text { públicos para a } \\
\text { fixação da população }\end{array}$ & & & & $X$ & $X$ & & & & \\
\hline $\begin{array}{ll}\begin{array}{l}\text { Potenciação } \\
\text { equipamentos }\end{array} & \text { de } \\
\end{array}$ & & & & $X$ & & & & $\mathrm{X}$ & \\
\hline
\end{tabular}

(C.1) Almeida; (C.2) C. Beira; (C.3) F.C. Rodrigo; (C.4) Guarda; (C.5) Manteigas; (C.6) Mêda; (C.7) Pinhel; (C.8) Sabugal; (C.9) Trancoso 
Em síntese, refletindo sobre a tensão enunciada no próprio título do trabalho: entre lógicas de sobrevivência e de desenvolvimento estratégico, concluímos que estamos perante uma situação em que os problemas do território, em boa verdade, já não dependem da ação dos seus intervenientes diretos, limitando-se estes a menorizar e a resolver pontualmente situações de pré rutura ou rutura (especialmente no que respeita à variável demográfica). Só através de políticas de âmbito mais global (das políticas nacionais, locais e transnacionais, nomeadamente da União Europeia), de valorização destes espaços de Interior, conjugando serviços públicos de apoio, valorizando as relações de proximidade e descriminando positivamente estes espaços, se conseguirá inverter estas tendências, resolvendo simultaneamente dois problemas: o do Interior com um 'repovoamento' e melhoria dos seus apports competitivos e o do Litoral que enferma de uma excessiva concentração populacional, ficando assim menos congestionado e de mais fácil gestão.

É neste contexto que poderemos encarar a atuação dos municípios na área educativa: procuram garantir, por um lado, os níveis mínimos de sobrevivência dos serviços destinados aos seus munícipes, e, por outro, arquitetar estratégias que permitam visualizar uma 'janela de esperança' para inverter o rumo dos acontecimentos. Este sentido estratégico, que deve forçosamente existir, mover-se-á num estreito corredor de oportunidades, que obrigará a repensar posturas até agora seguidas, a procurar pontos de apoio junto dos concelhos e estruturas mais próximas, a gerir recursos comuns de uma forma racional e equilibrada, que, baseando-se na Educação, possam atingir patamares de atratividade e de qualidade de vida.

\section{CONCLUSÃO}

Com o advento das sociedades modernas e com a complexidade crescente dos problemas que enfrentamos, a educação tornou-se "uma tarefa das escolas, das famílias, das comunidades locais, de toda a comunidade nacional, sendo por isso necessário que seja assumida como participação de todos na construção efetiva de um futuro melhor" (Almeida, 1995, p. 9). Para que a escola mude, deixando de estar isolada do "ambiente" que a rodeia, também é necessário que a comunidade mude. Nesta perspetiva, consideramos que as estratégias de Desenvolvimento Local (DL) devem assentar numa articulação entre o sistema educativo nacional, tendencialmente considerado distante e impessoal, e o espaço local envolvente, propício às relações de proximidade e sociabilidade e ao desenvolvimento territorial integrado.

No campo educativo tem-se verificado um considerável aumento de iniciativas ao nível local, na medida em que "o dinamismo local dos 
municípios, juntamente com as escolas e outros parceiros educativos, está a conquistar progressivos espaços de autonomia deixados em aberto pelo imobilismo e rigidez da administração de ensino centralizado que ainda predomina" (Fernandes, 1996, p. 119). Encontrando-se ligados umbilicalmente por laços de espacialidade, a Escola e o Município são parceiros indissociáveis do desenvolvimento de um território, valorizando as suas especificidades.

$\mathrm{O}$ estudo aqui apresentado sobre as tensões e as tendências reveladas pelas Cartas Educativas Municipais mostra uma realidade multifacetada a respeito da problemática do Desenvolvimento Local e da sua relação com a Educação. Atendendo à estrutura e conteúdo dos documentos analisados é possível inventariar algumas das suas características e problemas subjacentes:

1. Existem diferentes perspetivas na conceção dos documentos, levantando dificuldades em termos de comparação dos elementos apresentados;

2. Baseiam-se sobretudo na inventariação de recursos educativos de forma exaustiva limitando-se maioritariamente aos integrantes na estrutura educativa e não considerando os recursos do território;

3. Não identificam e problematizam claramente aquilo que se considera como "problema" e "potencial" do concelho;

4. Não incidem a análise na articulação funcional entre as escolas e o município;

5. Ignoram estruturas que estão fora do seu campo de ação direta, embora façam parte de um território educativo, não questionando minimamente a sua ação e importância no contexto em estudo;

6. São (na grande maioria dos casos) deficitárias em termos de reflexão sobre a situação concreta da Educação ao nível concelhio;

7. Carecem de informações quanto à metodologia adotada na sua elaboração (debate público), pressentindo-se um trabalho de mera recolha de informação;

8. Enquadram-se na maior parte dos casos numa visão subjugada a uma lógica escolar não abrindo efetivamente horizontes para o desenvolvimento integrado do território;

9. Em termos gerais considera-se que a filosofia inerente à elaboração de uma CE não foi conseguida e que apenas se cumpriu uma tarefa necessária para dar satisfação a um imperativo legal, neste longo remanso do nacional burocratismo.

Não transparece nesta análise uma ideia de 'municipalização' da educação, ou seja, a ideia de que os municípios possuem um conceito e 
uma política próprios sobre Educação que lhes permita estabelecer a diferença em relação aos restantes (limítrofes ou não). O que permitirá talvez distinguir cada um dos municípios é um conjunto de iniciativas avulsas, que, fruto de alguma capacidade financeira e algum espirito empreendedor, levou a que se visionassem diferenças pontuais, não demonstrando contudo, uma identidade educativa local com visão estratégica.

É também de estranhar que não tenham sido considerados nas CE recursos educativos variados (escolas profissionais, centros de formação profissional, equipamentos externos à escola de apoio à educação, movimento associativo, estruturas do campo social e cultural) que têm intervenção direta num processo vasto e complexo como é o da Educação. Este posicionamento mostra-nos que existe uma conceção minimalista da Educação, diretamente subsidiária de um posicionamento unidirecional, baseado na escola, menorizando ou mesmo desvalorizando aquilo que acaba por ser o maior educador: a sociedade local. Outro aspeto que a análise das $\mathrm{CE}$ demonstra é a (quase) completa ausência de sentido de colaboração com os municípios limítrofes. Esta insularização educativa - uma espécie de 'paroquialização' do Local - torna os municípios mais vulneráveis e com maiores custos de funcionamento.

\section{REFERÊNCIAS BIBLIOGRÁFICAS}

Almeida, A. (1995). A investigação e a qualidade da educação. In B. Campos (Org.) A investigação educacional em Portugal (pp. 9-10). Lisboa: IIE.

Bardin, L. (1977). Análise de conteúdo. Lisboa: Edições 70.

Bogdan, R. \& Biklen, S. (1994). Investigação qualitativa em educação: uma introdução à teoria e aos métodos. Porto: Porto Editora.

Duffy, B. (1997). Análise de dados documentais. In J. Bell (Org.) Como realizar um projecto de investigação (pp. 90-98). Lisboa: Gradiva.

Fernandes, A. (1991). Socialização e desenvolvimento dos comportamentos sociais. In E. Pires, A. Fernandes \& J. Formosinho (Org.) A construção social da educação escolar (pp. 135-148). Porto: Edições Asa.

Fernandes, A. (1996). Os municípios portugueses e a educação. As normas e as práticas. In J. BARROSO \& J. PINHAL (Orgs.), A administração da educação, Os caminhos da descentralização (pp.113-124). Lisboa: Edições Colibri.

Ferrão, J. (1997). Reconstruir o Interior Destruindo a Interioridade. In Perspectivas de Desenvolvimento do Interior. Lisboa: INCM.

Ghiglione, R. \& Matalon, B. (1997). O inquérito, teoria e prática. Oeiras: Celta Editora. 
Laville, C. \& Dionne, J. (1999). A construção do saber. Manual de metodologia da pesquisa em ciências humanas. Porto Alegre: Artmed.

Yin, R. (2005). Estudo de caso - Planeamento e método. S. Paulo: Bookman Ed. 